Southern Illinois University Carbondale

OpenSIUC

Publications

Department of Geography and Environmental

Resources

2005

\title{
Empirical Downscaling of Wind Speed Probability Distributions
}

\author{
S C. Pryor \\ Indiana University Bloomington \\ Justin T. Schoof \\ Southern Illinois University Carbondale, jschoof@siu.edu \\ RJ. Barthelmie \\ Riso National Laboratory
}

Follow this and additional works at: http://opensiuc.lib.siu.edu/gers_pubs

Part of the Physical and Environmental Geography Commons

Journal of Geophysical Research--Atmospheres, 110, D19109, doi:10.1029/2005JD005899.

Copyright 2005 by the American Geophysical Union.

\section{Recommended Citation}

Pryor, S C., Schoof, Justin T. and Barthelmie, RJ. "Empirical Downscaling of Wind Speed Probability Distributions." (Jan 2005).

This Article is brought to you for free and open access by the Department of Geography and Environmental Resources at OpenSIUC. It has been accepted for inclusion in Publications by an authorized administrator of OpenSIUC. For more information, please contact opensiuc@lib.siu.edu. 


\title{
Empirical downscaling of wind speed probability distributions
}

\author{
S. C. Pryor and J. T. Schoof ${ }^{1}$ \\ Atmospheric Science Program, Department of Geography, Indiana University, Bloomington, Indiana, USA \\ R. J. Barthelmie ${ }^{2}$ \\ Department of Wind Energy and Atmospheric Physics, Risø National Laboratory, Roskilde, Denmark \\ Received 18 February 2005; revised 9 May 2005; accepted 15 July 2005; published 13 October 2005.
}

[1] This paper presents a novel approach to developing empirically downscaled estimates of near-surface wind speed and energy density and results from application of the technique to multiple stations in northern Europe. The downscaling takes a probabilistic approach in that it uses the mean and standard deviation of relative vorticity at $500 \mathrm{hPa}$ and mean sea level pressure gradients computed using output from the ECHAM4/OPYC3 atmosphere-ocean general circulation model as the predictors and parameters of the wind speed probability distribution at surface stations as the predictands. We demonstrate that this approach generates accurate depictions of the wind climate during the conditioning period and then apply the downscaling technique to examine changes between 1961-1990 and 2071-2100, which are compared to the results of dynamical downscaling. The empirically downscaled results for 1961-1990 and 2071-2100 show some evidence for small decreases in mean wind speed, 90th percentile wind speed, and energy density in 2071-2100 relative to 1961-1990. The projected changes are larger than the mean errors in the training period but smaller than current interannual variability. Rossby Centre regional climate model (RCM)-derived grid cell mean wind speeds exhibit a high degree of agreement with the empirically downscaled station wind speeds. However, in contrast to the empirical downscaling, simulations conducted using the Rossby Centre RCM indicate evidence for a small increase in the annual wind energy resource over northern Europe between the end of the 20th century and the end of the 21st century.

Citation: Pryor, S. C., J. T. Schoof, and R. J. Barthelmie (2005), Empirical downscaling of wind speed probability distributions, J. Geophys. Res., 110, D19109, doi:10.1029/2005JD005899.

\section{Introduction}

[2] Trends in near-surface wind speeds are acknowledged as having particular importance for climate change impacts on society (e.g., the insurance industry [Changnon et al., 1999], coastal erosion [Viles and Goudie, 2003], forest and infrastructure damage [Jungo et al., 2002], storm surges [Bijl, 1997], and air-sea exchange [Latham and Smith, 1990]). They also have relevance for applications such as wind energy resource estimation [Pryor et al., 2005b] and construction issues [Ambrose and Vergun, 1997].

[3] Surface wind speeds exhibit variability at much smaller spatial scales than typify the resolution of coupled atmosphere-ocean general circulation models (AOGCM) $\left(\mathrm{O}\left(2^{\circ} \times 2^{\circ}\right)\right)$ and hence there is a need to develop tools for downscaling AOGCM projections to generate finerscale projections of near-surface wind climatologies. This downscaling can be undertaken using either (1) physical/

\footnotetext{
${ }^{1}$ Now at Center for Ocean-Atmospheric Prediction Studies, Florida State University, Tallahassee, Florida, USA.

${ }^{2}$ Also at Atmospheric Science Program, Department of Geography, Indiana University, Bloomington, Indiana, USA.

Copyright 2005 by the American Geophysical Union. 0148-0227/05/2005JD005899\$09.00
}

dynamical methods, where a numerical model (e.g., regional climate model (RCM)) is used to produce finer resolution fields of the parameter of interest from the large-scale description of climate produce by the AOGCM (e.g., the work by Dickinson et al. [1989] and Giorgi et al. [1992] and the review by Giorgi and Mearns [1999]) or (2) statistical/ empirical methods, where a transfer function is developed that statistically relates large-scale climate parameters generated by AOGCM to the near-surface parameter of interest (see the review by von Storch et al. [2000]). In empirical downscaling, a transfer function is derived from either historical relationships between the differing scales (analogous to the Perfect Prog. approach to weather forecasting) [Huth, 2004] or based on GCM output for the current climate related to the near-surface observation [Sailor and $\mathrm{Li}, 1999$ ] (analogous to the model output statistics (MOS) approach to forecasting, and which is also referred to as climatological projection by model statistics (CPMS) by Karl et al. [1990]).

[4] Downscaling conducted within a dynamical framework is theoretically preferable and can be conducted for any location regardless of data availability. RCMs do not require specific training and can respond in physically consistent ways to external conditions not realized in the training period. Deriving realistic scenarios from empirical 


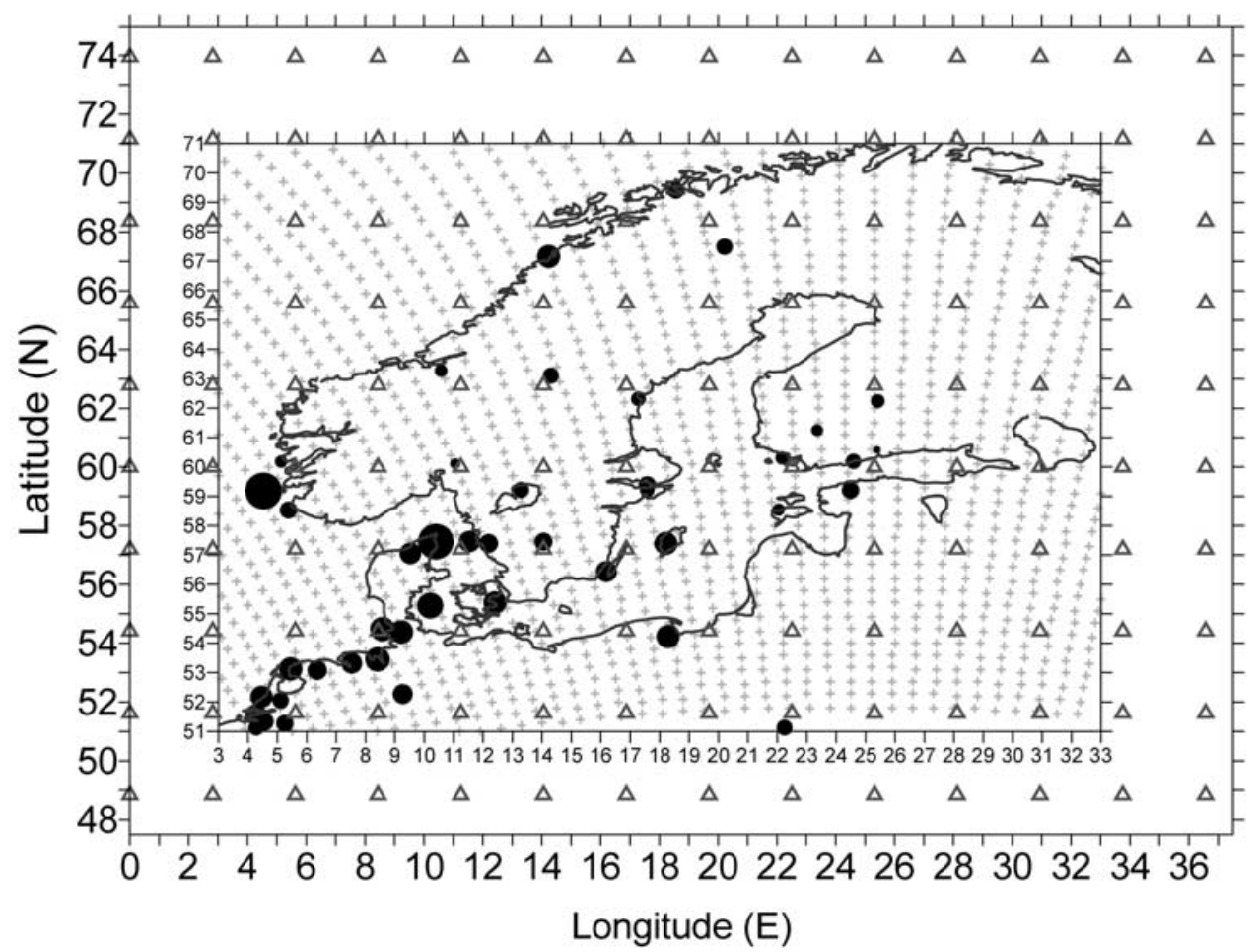

Figure 1. The study domain, coastline, RCAO grid output (pluses), and station locations (circles). The size of the circle shown at each site indicates the mean wind speed (1982-2002) derived from the observational record. The scale used to depict the magnitude of the mean wind speed is linear (the dot diameter spans a factor of 5 , while the data range is $2.9-10.2 \mathrm{~m} \mathrm{~s}^{-1}$ ). The outer grid shows the domain from which the ECHAM4/OPYC3 data were extracted for use in the evaluation and the downscaling. The centroids of the ECHAM4/OPYC3 grids are indicated by the triangles.

tools is reliant on strong and stationary relationships between predictor(s) and predictand. However, empirical downscaling may be undertaken without requiring additional data such as detailed surface morphology maps, and is computationally more efficient. Likely the relative strengths and weaknesses of each downscaling method depend on the variable being downscaled and the specific application. For example, see Wilby et al. [2000] for a comparison of advantages and disadvantages of dynamical downscaling by a RCM with empirical downscaling for applications to a specific hydrological problem. Since few attempts to downscale wind climates have been undertaken, it is necessary to consider whether empirical or dynamical downscaling yield the best results. In this article we describe a technique for empirically downscaling wind data and compare the downscaled wind speed parameters and the energy density to dynamically downscaled wind climates over northern Europe [Pryor et al., 2005a].

\section{Objectives}

[5] The analyses described herein are focused on northern Europe and specifically the Baltic region (see Figure 1) and were undertaken with three primary objectives: (1) to develop novel techniques for empirically downscaling wind speed probability distributions and wind energy density from AOGCM output, (2) to apply empirical downscaling tools to transient ECHAM4/OPYC3 AOGCM output to determine if substantial changes in wind speed and energy density are projected for 2071-2100 relative to the end of the 20th century $(1961-1990)$, and (3) to compare the results from empirically downscaled wind speed and energy density with those derived from dynamical downscaling for this region [Pryor et al., 2005a]. A MOS based empirical downscaling approach inherently accounts for model bias and is adopted here because of difficulties with conditioning transfer functions on a common time index when the AOGCM represents a plausible time course of conditions that may not be synchronized with the observed time series of the predictands.

[6] Most previous empirical downscaling has been undertaken with the objective of obtaining a high-resolution (in space and time) series of realization of the parameter of interest. However, because of (1) the difficulty in reproducing the time structure of geophysical parameters [Huth et al., 2001] (as Allen and Ingram [2002] state, "we cannot hope to predict the exact climate of 2050 , still less the weather on a particular day") and (2) knowledge that for many applications a description of the frequency distribution of wind speeds is the desired product, we present empirical downscaling focused on the parameters of the wind speed probability distribution rather than generation of a time series. It is worthy of note that, if the descriptors of the probability distribution are known, a synthetic data set can always be generated that conforms to that distribution if a time series is required. It is hoped this approach will (1) avoid a focus on mean conditions and underestimation of variance (due to truncation of the probability distribution) that has 
been observed in previous downscaling research [e.g., Evans et al., 2004; Buishand and Brandsma, 2001; Lynn et al., 2004; Schnur, 2002] and (2) generate output that is accessible to, and more strongly coupled to, the needs of user communities that may have specific interest in, for example, changes in the upper percentiles of geophysical parameters [Zhang et al., 2004; Christensen and Christensen, 2003; Cavazos and Rivas, 2004; Klein Tank et al., 2005].

[7] A probabilistic approach to climate projections has also been advocated in the RCM community where probability estimates from model ensembles have been derived [Palmer and Räisänen, 2002; Stainforth et al., 2005; Giorgi and Mearns, 2002]. It is important to emphasize that our approach is not directly analogous to probabilistic projections determined from multimodel ensembles, since a single statistical model is used to derive the distribution parameters, though it may be possible to extend this approach to include output from multiple suites of predictors, or to "dressing" of the projections using historical error statistics as advocated by Roulston and Smith [2003].

\section{Data}

\subsection{ECHAM4/OPYC3}

[8] Output from the ECHAM4/OPYC3 [Roeckner et al., 1999 ] coupled AOGCM (spectral resolution T42, $\approx 2.8^{\circ} \times$ $2.8^{\circ}$ ) was used to provide data for calculating the predictors used in the empirical downscaling and the boundary conditions for the RCM simulations. The downscaling predictors computed for $47.5^{\circ}-75^{\circ} \mathrm{N}$ and $0^{\circ}-37.5^{\circ} \mathrm{E}$ are (1) the mean and standard deviation of relative vorticity calculated from the 12 GMT simulations of $500 \mathrm{hPa} \mathrm{u}$ and v components of the wind and (2) the mean sea level pressure gradient computed from the 12 GMT sea level pressure fields. We use 1982-2002 to condition the downscaling algorithms and then apply the resulting transfer functions to output from ECHAM4/OPYC3 simulation of 1961-1990 and the A2 emission scenario [Intergovernmental Panel on Climate Change (IPCC), 2000] for a climate change projection period of 2071-2100.

\subsection{NCEP/NCAR Reanalysis (NNR)}

[9] To provide independent assessment of ECHAM4/ OPYC3 simulation of the downscaling predictors we use pressure gradients derived from mean sea level pressure fields and relative vorticity from the $\mathrm{u}$ and $\mathrm{v}$ wind components at $500 \mathrm{hPa}$ from the NCEP/NCAR reanalysis (NNR) data set [Kalnay et al., 1996; Kistler et al., 2001]. The atmospheric model used to generate the NNR fields is spectral triangular (T62) with transformation to a Gaussian grid (approx. horizontal resolution of $210 \mathrm{~km}$ ) for calculation of nonlinear quantities and physics. The mean sea level pressure fields and wind components at $500 \mathrm{hPa}$ are archived at $2.5 \times 2.5^{\circ}$ resolution.

\subsection{Rossby Centre Coupled RCM (RCAO)}

[10] The RCM simulations used in this research were conducted using the Rossby Centre coupled RCM (RCAO) [Räisänen et al., 2003, 2004]. Boundary conditions for the simulations were derived from the same simulations with ECHAM4/OPYC3 that are used in the empirical downscal- ing. The atmospheric component of the RCAO model was run in a rotated longitude-latitude grid with $0.44 \times 0.44^{\circ}$ resolution $(106 \times 102$ grid cells $)$. Here we use the 1200 GMT output from the RCAO ( $\mathrm{u}$ and $\mathrm{v}$ components of the flow) in the area shown in Figure 1 for two simulations: (1) 19611990 and (2) the A2 scenario for 2071-2100. Wind speeds at 10 -m height were derived from the lowest RCAO layer (at 90-m) based on the prevailing stability as described by Pryor et al. [2005a]. Evaluation of RCAO simulations of wind speed and energy density [Pryor et al., 2005a; Räisänen et al., 2003, 2004] indicate simulated wind fields from RCAO during the control period (1961-1990) exhibit reasonable and realistic features as documented in reanalysis data products with respect to the spatial patterns and absolute magnitude of the wind speed parameters. However, the Weibull k parameter from RCAO is $0.1-0.2$ higher than in the NNR data and RCAO simulated wind speeds in the northwest of the domain are biased low relative to the NNR data. When the RCAO output were aggregated within each of the NNR grids and the spatial fields of mean wind speed were compared to those from the NNR data set it was determined that the RCAO was biased slightly low leading to an average mean absolute difference (MAD) in the wind speeds of $0.49 \mathrm{~m} \mathrm{~s}^{-1}$, a root mean square difference (RMSD) of $0.65 \mathrm{~m} \mathrm{~s}^{-1}$ (relative to a mean wind speed of $4.79 \mathrm{~m} \mathrm{~s}^{-1}$ ) and a correlation coefficient of 0.41 [Pryor et al., 2005a].

\subsection{Near-Surface Wind Speeds}

[11] Near-surface wind speeds were extracted from hourly or 3-hourly data from two sources: (1) international surface weather observations (1982-1997) and (2) integrated surface hourly observations (1995-2002). Both data products are available from the National Climatic Data Center (NCDC) (see http://www.ncdc.noaa.gov/oa/climate/ climateproducts.html). Time series of the 12 GMT observation of wind speed were extracted from stations with the study region $\left(51^{\circ}-71^{\circ} \mathrm{N}\right.$ and $\left.3^{\circ}-33^{\circ} \mathrm{E}\right)$ for the period 1982-2002. For comparability with the RCM-derived downscaling, we interpolated the wind speeds from measurement height to 10-m using the power law [Hsu, 1988]:

$$
\frac{u_{1}}{u_{2}}=\left(\frac{z_{1}}{z_{2}}\right)^{\frac{1}{7}}
$$

where $\mathrm{u}$ is the wind speed and $\mathrm{z}$ is height.

[12] The power law was used to extrapolate the profile rather than the logarithmic wind profile because it may be applied without information about the local roughness length at each station.

[13] Because it is an implicit assumption of our proposed downscaling technique that the Weibull distribution is a good descriptor of wind speed probability distributions [Conradsen et al., 1984; Pavia and O'Brien, 1986; Pryor et al., 2004; Seguro and Lambert, 2000], prior to inclusion in the analysis data from each site were evaluated by testing the degree of fit to a Weibull distribution for data from (1) the entire data set (all observations from 1982-2002), (2) each calendar month (e.g., all data from January 1982-2002), and (3) the winter season (i.e., all data from December-February 1982-2002) when highest energy density is observed in the study region [Pryor et al., 2005a]. Any site for which the 
probability distribution did not conform to a Weibull distribution was excluded from the downscaling analysis. This screening procedure excluded 20 stations, nearly all of which had data stored only as whole integer wind speeds in $\mathrm{m} \mathrm{s}^{-1}$, leaving 46 stations for use in the empirical downscaling.

\section{Methods}

\subsection{Downscaling Predictors}

[14] The large-scale predictors selected a priori for the empirical downscaling are $(1)$ relative vorticity $(\zeta)$ computed at $500 \mathrm{hPa}$ based on the archived $\mathrm{u}$ and $\mathrm{v}$ components of the wind speed fields and (2) sea level pressure gradients (computed as the maximum between adjacent grid points in any of 8 directions) derived based on archived mean sea level pressure fields. Vorticity was selected for inclusion in the analysis as a metric of the degree of vertical motion at the synoptic scale and hence likely coupling of the nearsurface atmosphere to higher wind speeds aloft. A height of $500 \mathrm{hPa}$ was selected for calculation of relative vorticity because the topography within parts of the study domain (the Scandinavian Mountain Range) approach elevations of $2.5 \mathrm{~km}$ and hence may significantly impact the flow at $700 \mathrm{hPa}$. The mean sea level pressure gradients were selected to represent the near-surface regional forcing of winds.

[15] Although we adopt a MOS based approach to the downscaling, to quantify how well the predictor variables and the fields from which they are derived are simulated by the AOGCM we compared them with NNR data. The ability of a model to properly simulate any field depends on the models ability to simulated both the pattern and its magnitude. We therefore evaluate our predictor fields using three quantities: the correlation coefficient $(\mathrm{r})$, the root mean square difference (RMSD) (both the systematic $(\overline{E r})$ and nonsystematic $\left(E r^{\prime}\right)$ terms), and the standard deviations of the values comprising the modeled $\left(\sigma_{\mathrm{m}}\right)$ and observed $\left(\sigma_{\mathrm{o}}\right)$ fields. These quantities are related according to

$$
E r^{\prime 2}=\sigma_{m}^{2}+\sigma_{o}^{2}-2 \sigma_{m} \sigma_{o} r
$$

As shown by Taylor [2001], this relationship allows these three evaluation statistics to be plotted on a single twodimensional diagram, thereby allowing easy comparison of multiple models, variables, and/or time periods. While Taylor diagrams have been adopted by both the IPCC [McAvaney et al., 2001] and AOGCM intercomparison studies at the global scale [Covey et al., 2003], we use them here to demonstrate the ability of ECHAM4/OPYC3 to simulate the predictor variables at the regional scale.

\subsection{Downscaling Predictands}

[16] In this research we use the two parameter Weibull probability density function [Troen and Petersen, 1989] to represent the wind speed probability distribution:

$$
p(U) \equiv \frac{k}{A}\left(\frac{U}{A}\right)^{k-1} \exp \left[-\left(\frac{U}{A}\right)^{k}\right] \text { for } U \geq 0, A>0, k>0
$$

where $\mathrm{k}$ is a dimensionless shape parameter (related to the "peakedness" of the distribution), A is the scale parameter (related to the mean of the distribution), $\mathrm{U}$ is the time series
Table 1. Regression Equations Formulated for the Weibull Parameters for Data From Copenhagen in Denmark ${ }^{\mathrm{a}}$

\begin{tabular}{lcccc}
\hline & $\overline{\mathrm{PG}}$ & $\bar{\zeta}$ & $\sigma(\zeta)$ & $\mathrm{r}^{2}$ \\
\hline Weibull A & $-277.2^{\mathrm{b}}$ & $-4.340^{\mathrm{b}}$ & $5.118^{\mathrm{b}}$ & 1.00 \\
Weibull k & $-174.0^{\mathrm{b}}$ & $-1.662^{\mathrm{c}}$ & $2.066^{\mathrm{b}}$ & 0.97 \\
\hline${ }^{\mathrm{a}}$ Here $\mathrm{n}=12$. & & & \\
${ }^{\mathrm{b}}$ Coefficients are significantly different to 0 at the $95 \%$ confidence level. \\
${ }^{\mathrm{c}}$ Coefficients are significantly different to 0 at the $80 \%$ confidence level.
\end{tabular}

of wind speed observations, and $\mathrm{p}(\mathrm{U})$ is the probability density function. The cumulative distribution function, $\mathrm{P}(\mathrm{U})$, is given by

$$
P(U) \equiv 1-\exp \left[-\left(\frac{U}{A}\right)^{k}\right]
$$

and can be used to compute an "expected" energy density:

$$
E=\frac{1}{2} \rho A^{3} \Gamma\left(1+\frac{3}{k}\right)
$$

where $\Gamma$ is the gamma function and $\rho$ is air density.

[17] The Weibull distribution parameters can be derived from, or used to derive, other descriptors of the probability distribution as follows:

$$
\begin{gathered}
\bar{U}=A \Gamma\left(1+\frac{1}{k}\right) \\
U_{50 \%}=A(\ln 2)^{1 / k} \\
U_{90 \%}=A(-1 * \ln (0.1))^{1 / k}
\end{gathered}
$$

where $\overline{\mathrm{U}}$ is the mean wind speed, $\mathrm{U}_{50 \%}$ is the median wind speed, and $U_{90 \%}$ is the 90th percentile wind speed (p90).

[18] There are a number of approaches to fitting a Weibull distribution [Pryor et al., 2004]. Here we fit the distribution parameters using the mean and median values (equations (6) and (7)) because these properties are relatively robust to the low resolution (single decimal place at best) at which the wind speed data were archived.

\subsection{Downscaling Methodology}

[19] Our downscaling methodology is based on multiple linear regression, in which the monthly station-specific Weibull parameters (computed from 21 years of observed data) are the predictands and the monthly means and standard deviations of AOGCM-derived relative vorticity $(\zeta)$ and mean sea level pressure gradients (PG) are the predictors. This generates a sample of 12 values for each of the parameters (one for each month) that are used to derive a regression equation for each of the Weibull parameters, for example,

$$
A_{i}=c_{1} * \overline{P G_{j}}+c_{2} * \overline{\zeta_{j}}+c_{3} * \sigma\left(\zeta_{j}\right)
$$

Where $\mathrm{i}$ is the station, and $\mathrm{j}$ is the value of the circulation parameters for the ECHAM4/OPYC3 grid cell containing 

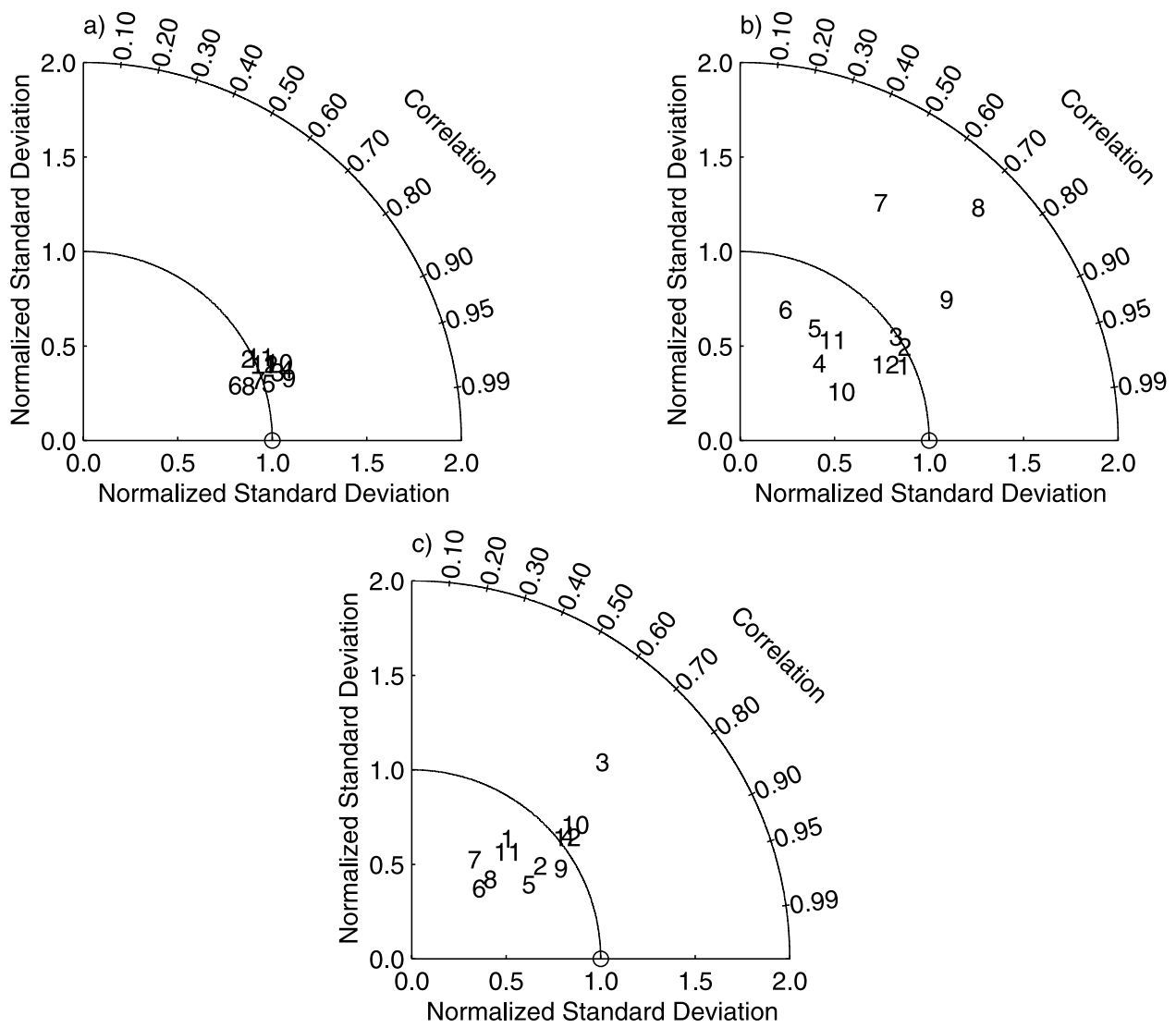

Figure 2. Taylor diagrams for (a) mean sea level pressure gradient, (b) mean relative vorticity, and (c) standard deviation of relative vorticity. The radial axis indicates the correlation between the observed (NNR) and simulated (ECHAM4/OPYC3) fields. The horizontal and vertical axes represent the normalized standard deviation (i.e., the standard deviation of values comprising the modeled field divided by the standard deviation of the values comprising the observed field). The distance between the origin (circle) and any point is proportional to the root mean squared difference. Each number indicates a month (e.g., 1 is January, 2 is February, etc.).

the station. $A_{i}, \overline{P G_{j}}, \overline{\zeta_{j}}$ and $\sigma\left(\zeta_{j}\right)$ are vectors of 12 values (one for each month).

[20] Use of data at the monthly timescale to condition the downscaling equations allows representation of a range of realizations of all parameters. Further, inclusion of each of the predictors increased the variance explanation for either Weibull A or k parameters. An example of the regression coefficients derived using this approach is given in Table 1. As shown, use of these predictors leads to high variance explanation for both Weibull parameters.

[21] Once the regression equations were determined for each site they are then applied to the mean and standard deviation of $\zeta$ and mean PG from the ECHAM4/OPYC3 output for 1982-2002, 1961-1990, and 2071-2100 to derive the Weibull $\mathrm{A}$ and $\mathrm{k}$ parameters for each station. These parameters are then used to compute the mean wind speed (using equation (6)), 90th percentile wind speed (equation (8)) and energy density (equation (5)).

\section{Results}

\subsection{Evaluation of the AOGCM Simulation of the} Predictor Variables

[22] To assess the realism of the predictor variable simulation by ECHAM4/OPYC3, Taylor diagrams (section 4.1) were constructed using NNR and ECHAM4/OPYC3 data from 1953-2001. For each data set, the means and standard deviations of the grid point predictors were computed on the original model grid. For computation of the quantities needed for the Taylor diagrams, the NNR means and

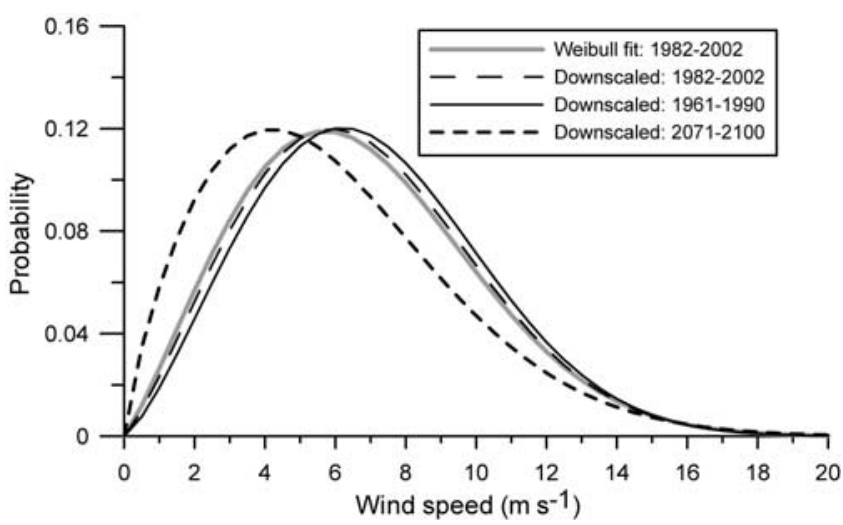

Figure 3. The probability distribution of wind speed at the Copenhagen station derived from direct Weibull fit to the observations and the downscaling of the Weibull $\mathrm{A}$ and $\mathrm{k}$ parameters for 1982-2002, 1961-1990, and 2071-2100. 
(a)

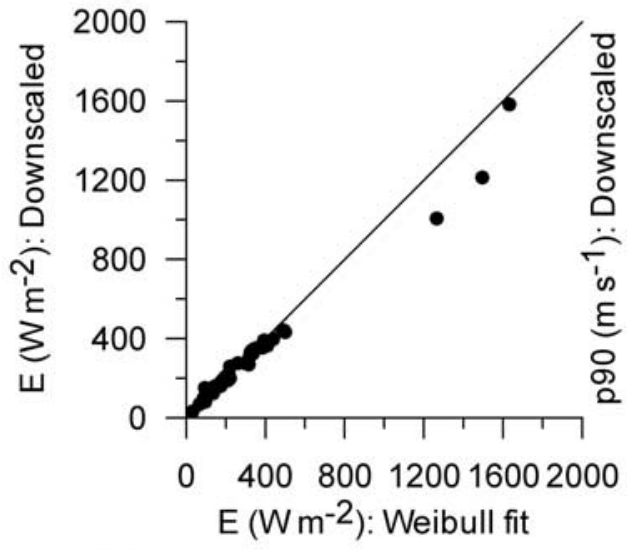

(d)

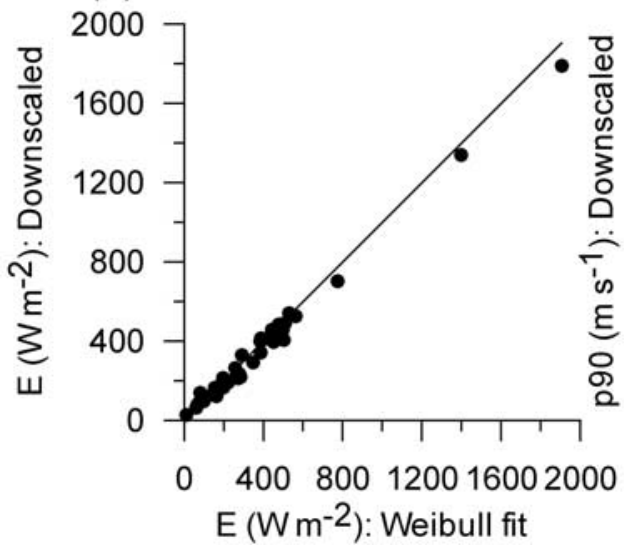

(b)

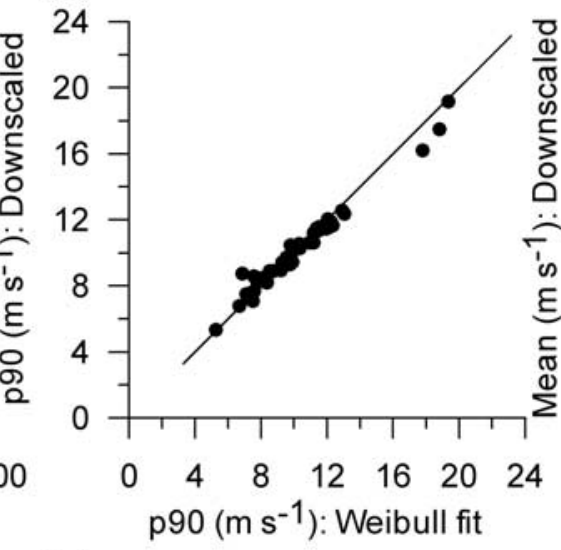

(e) (c)

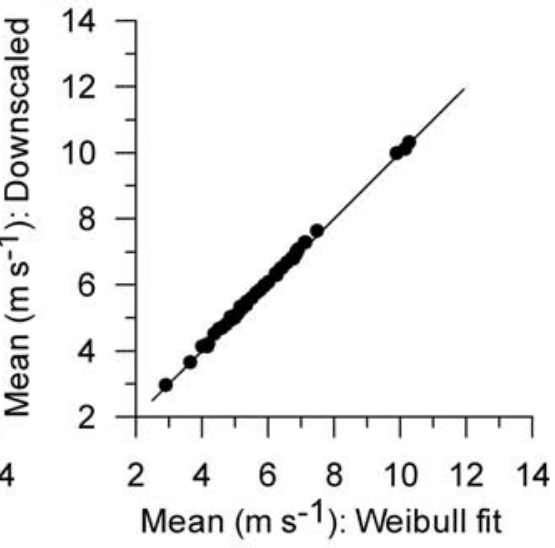

(f)
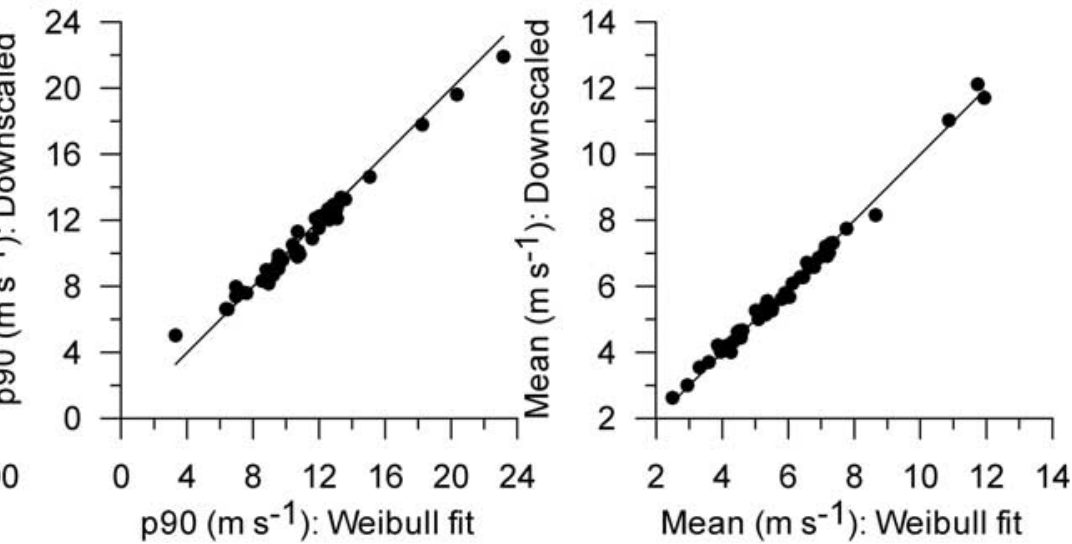

Figure 4. Scatter diagrams of (a, d) the energy density (E), (b, e) 90th percentile wind speed (p90), and (c, f) mean wind speed (Mean) at each of the 46 stations derived directly from the Weibull fit to the data for 1982-2002 and from downscaling based on the relative vorticity and sea level pressure gradients. Figures $4 \mathrm{a}-4 \mathrm{c}$ show data from the entire period 1982-2002, while Figures $4 \mathrm{~d}-4 \mathrm{f}$ show data for the winters of $1982-2002$.

Table 2. Descriptive Statistics Between Energy Density, 90th Percentile Wind Speed, and Mean Wind Speed Values Computed Directly From the Observed Data and Using the Downscaling for the Control Period (1982-2002) ${ }^{\mathrm{a}}$

\begin{tabular}{|c|c|c|c|c|}
\hline & Mean & $\begin{array}{l}\text { Correlation } \\
\text { Coefficient } \mathrm{r} \\
\end{array}$ & $\begin{array}{c}\text { Mean } \\
\text { Absolute } \\
\text { Difference } \\
\end{array}$ & $\begin{array}{c}\text { Root Mean } \\
\text { Square } \\
\text { Difference } \\
\end{array}$ \\
\hline \multicolumn{5}{|l|}{ Energy Density, $\mathrm{W} \mathrm{m}^{-2}$} \\
\hline 1982-2002: downscaled versus calculated from the Weibull fit to the data & 318 & 0.99 & 30 & 61 \\
\hline Winter data from 1982-2002: downscaled versus calculated from the Weibull fit to the data & 399 & 1.00 & 40 & 76 \\
\hline $1961-1990$ versus $2071-2100$ annual downscaled data & 312 & 0.98 & 61 & 97 \\
\hline $1961-1990$ versus $2071-2100$ winter downscaled data & 389 & 0.96 & 154 & 245 \\
\hline \multicolumn{5}{|l|}{ 90th Percentile Wind Speed, $\mathrm{m} \mathrm{s}^{-1}$} \\
\hline 1982-2002: downscaled versus calculated from the Weibull fit to the data & 10.35 & 0.99 & 0.37 & 0.54 \\
\hline Winter data from 1982-2002: downscaled versus calculated from the Weibull fit to the data & 10.94 & 0.99 & 0.44 & 0.56 \\
\hline $1961-1990$ versus $2071-2100$ annual downscaled data & 10.40 & 0.98 & 0.67 & 0.80 \\
\hline $1961-1990$ versus $2071-2100$ winter downscaled data & 11.00 & 0.95 & 1.03 & 1.26 \\
\hline \multicolumn{5}{|l|}{ Mean Wind Speed, $\mathrm{m} \mathrm{s}^{-1}$} \\
\hline 1982-2002: downscaled versus calculated from the Weibull fit to the data & 5.88 & 0.99 & 0.10 & 0.11 \\
\hline Winter data from 1982-2002: downscaled versus calculated from the Weibull fit to the data & 6.04 & 1.00 & 0.15 & 0.18 \\
\hline $1961-1990$ versus $2071-2100$ annual downscaled data & 6.14 & 0.93 & 0.80 & 0.91 \\
\hline $1961-1990$ versus $2071-2100$ winter downscaled data & 6.48 & 0.94 & 0.99 & 1.15 \\
\hline
\end{tabular}

aAlso shown are comparisons of values downscaled for 1961-1990 and 2071-2100. The "Mean" column shows the mean value of the parameter (energy density, 90th percentile, and mean wind speed) during 1982-2002 or 1961-1990 computed from the 46 stations. 
(a)

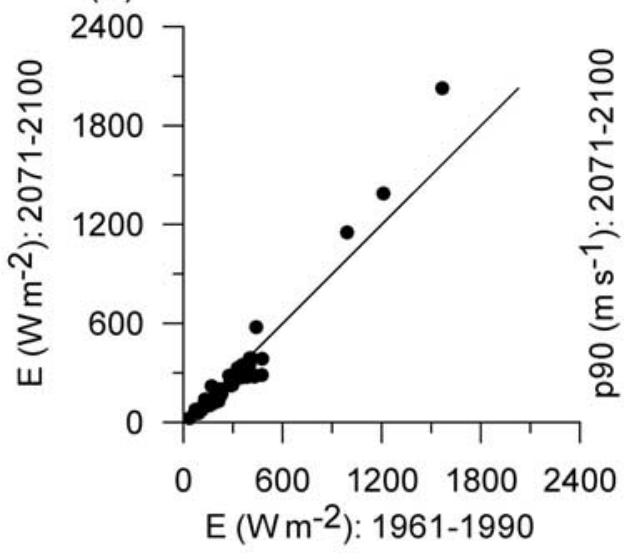

(d)

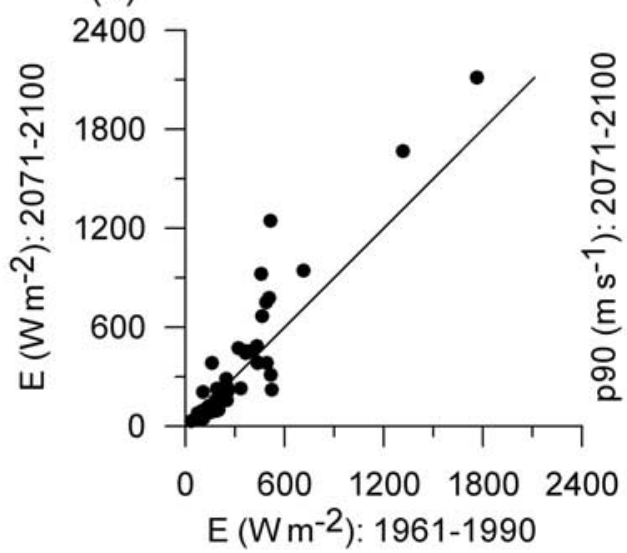

(b)

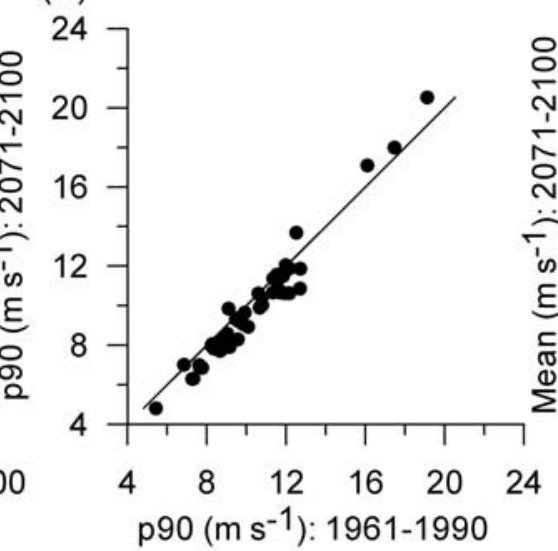

(e)

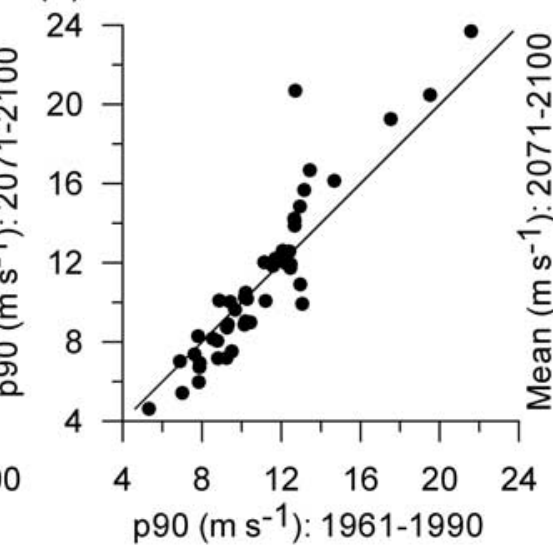

(c)

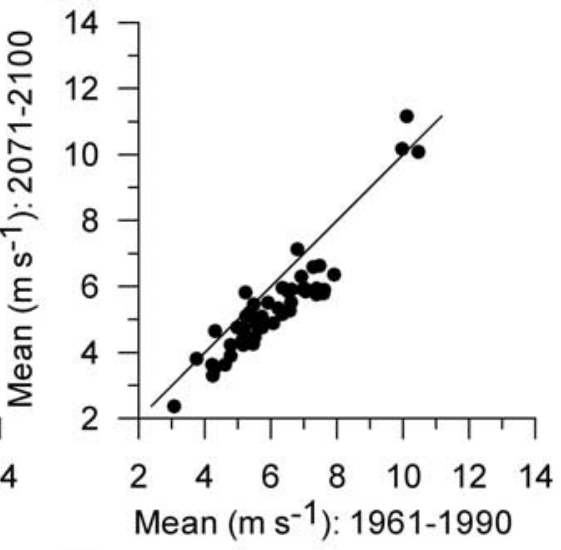

(f)

Figure 5. Scatter diagrams of (a, d) the energy density (E), (b, e) 90th percentile wind speed (p90), and (c, f) mean wind speed (Mean) at each of the 46 stations derived from downscaling of data for 19611990 and 2071-2100. Figures 5a-5c show data from the entire period, while Figures $5 \mathrm{~d}-5 \mathrm{f}$ show data for the winters.

standard deviations were interpolated to the ECHAM4/ OPYC3 grid using inverse distance weighted interpolation. During each month, the correlation between ECHAM4/ OPYC3- and NNR-derived mean sea level pressure gradient fields is $>0.88$ (Figure 2a). The level of variability in this field is also well simulated by ECHAM4/OPYC3 (as indicated by a normalized standard deviation close to one during all months). While there is considerable variability in the monthly performance of ECHAM4/OPYC3 with respect to relative vorticity (Figures $2 \mathrm{~b}$ and $2 \mathrm{c}$ ), the comparison between observations and model simulations yields excellent agreement during winter, when wind energy in the study region is generally at its maximum [Pryor et al., 2005a]. Examination of the monthly mean fields (not shown) indicates that during the summer months, both NNR and ECHAM4/OPYC3 produce a dipole pattern with positive $\zeta$ in the southern part of the domain and negative $\zeta$ in the northern Baltic region. However, this pattern is more pronounced in ECHAM4/OPYC3, resulting in an overestimation of the variability in the mean fields during these months. During spring, the pattern is shifted northeastward and the ECHAM4/OPYC3 simulated pattern is less pronounced relative to NNR. The standard deviations of ECHAM4/OPYC3-derived $\zeta$ exhibit slightly better agreement with the NNR-derived fields (Figure 2c), although the standard deviations of $\zeta$ exhibit less spatial variability than the other fields tested.

\subsection{Evaluation of the Empirical Downscaling Approach}

[23] Figure 3 shows an example of the wind speed probability distribution of data from Copenhagen, Denmark derived directly from observations and using the downscaling technique. As shown the wind speed probability distribution derived from the Weibull fit to the data is virtually indistinguishable from that derived using the downscaled Weibull parameters for 1982-2002. The probability distribution downscaled for 1961-1990 is also very similar to the period used to condition the downscaling algorithms but exhibits a slightly higher frequency of wind speeds above about $6 \mathrm{~m} \mathrm{~s}^{-1}$. The probability distribution derived for 2071-2100 from downscaling of the Weibull parameters differs due to an decrease in both the Weibull A and $\mathrm{k}$ parameters leading to a higher frequency of wind speeds below $5 \mathrm{~m} \mathrm{~s}^{-1}$.

[24] Observed and downscaled energy density, 90th percentile wind speed, and mean wind speed for 1982-2002 at each of the sites are depicted in Figure 4. The upper frames show the entire period of 1982-2002, while the frames below show the winter season. Descriptive statistics of the degree of association between the "observed" energy 
(a)
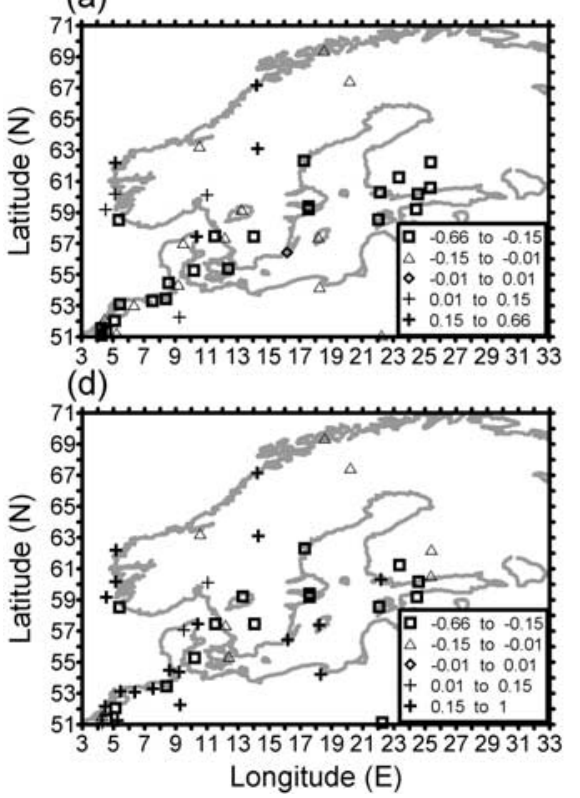

(b)

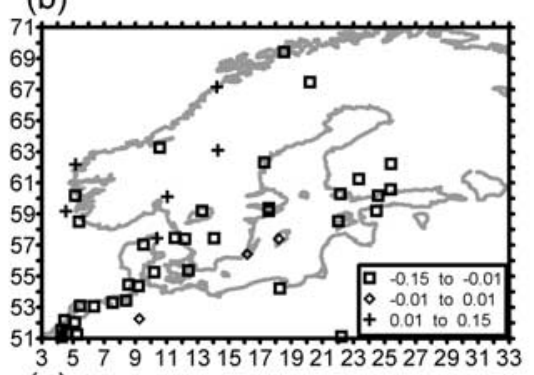

(e)

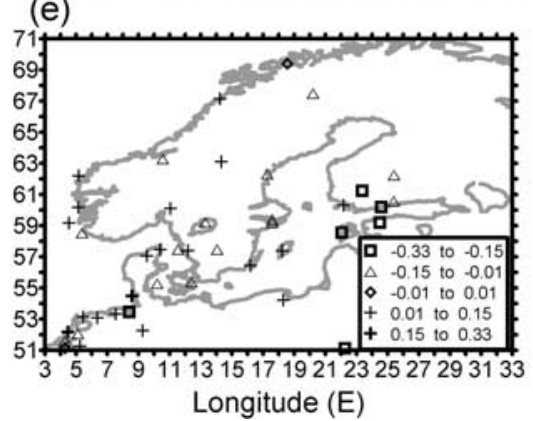

(c)

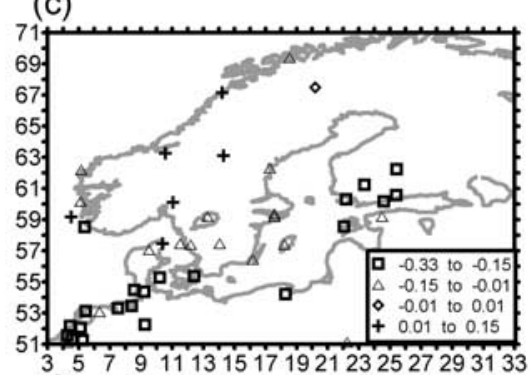

(f)

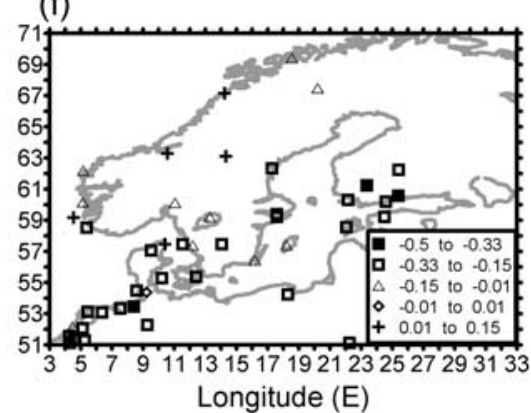

Figure 6. Normalized change in energy density, 90th percentile wind speed, and mean wind speed between 1961-1990 and 2071-2100. Changes in (a) energy density, (b) 90th percentile wind speed, and (c) mean wind speed computed for the entire periods. (d-f) Same normalized changes but for the wintertime only. The normalized change is calculated as $(2071-2100-1961-1990) /(1961-1990)$.

density, 90th percentile wind speed and mean wind speed and these values derived from the downscaling equations are presented in Table 2. As shown, the correlation between the parameters determined directly to those downscaled from the relative vorticity and the sea level pressure gradients exceeds 0.98 for each variable over the entire period (1982-2002) and in the winter season indicating that the downscaling technique maintains the majority of the station-to-station variability manifest in the observational records. Further, the MAD and RMSD are $<20 \%$ of the mean energy density during $1982-2002,<6 \%$ of the mean 90th percentile wind speed and $<4 \%$ of the average mean wind speed. When considering these statistics it is important to note that although the downscaling transfer functions were conditioned on the 1982-2002 data, because these equations were derived using monthly data, the annual and winter periods of 1982-2002 are to some degree independent of the training data.

\subsection{Empirically Downscaled Wind Speed Parameters for 1961-1990 and 2071-2100}

[25] Figure 5 shows scatter diagrams of the energy density, 90th percentile wind speed and mean wind speed derived from downscaling of data for 1961-1990 and
2071-2100, while Table 2 shows descriptive statistics of these data. As shown, the differences between 1961-1990 and 2071-2100 averaged over the 46 stations exceed the uncertainty associated with the downscaling procedure as measured in comparison of the 'observed' and downscaled data for 1982-2002. The MAD between the energy density computed directly from the observations from 1982-2002 versus the downscaled value averaged over the 46 stations is $30 \mathrm{~W} \mathrm{~m}^{-2}$, while the downscaled energy density for $1961-$ 1990 and 2071-2100, again averaged over the 46 stations, differs by over $60 \mathrm{~W} \mathrm{~m}^{-2}$. The majority of stations exhibit lower energy density, 90th percentile wind speed and the mean wind speed in the 2071-2100 projection period (Figure 6). While nearly all stations exhibit lower mean wind speeds in 2071-2100 there is evidence, especially during winter, of increases in the 90th percentile wind speed and energy density at several sites indicating a broadening of the probability distribution resulting in an increase of the upper percentiles. As shown in Table 3, over half of the stations exhibit a $>1 \%$ decrease in energy density, 90th percentile wind speed and mean wind speed between 1961-1990 and 2071-2100, and over two thirds of the stations exhibit a $>1 \%$ decrease in winter mean wind speed in the later period. Stations that indicate

Table 3. Number of Stations That Exhibit Normalized Changes in Energy Density, 90th Percentile Wind Speed, and Mean Wind Speed Between 1961-1990 and 2071-2100 in each of the Classes Shown in Figure 6

\begin{tabular}{|c|c|c|c|c|c|c|c|c|}
\hline \multicolumn{3}{|c|}{ Energy Density } & \multicolumn{3}{|c|}{ 90th Percentile Wind Speed } & \multicolumn{3}{|c|}{ Mean Wind Speed } \\
\hline Classes & Entire Year & Winter & Classes & Entire Year & Winter & Classes & Entire Year & Winter \\
\hline-0.66 to -0.15 & 23 & 16 & -0.33 to -0.15 & & 6 & -0.50 to -0.33 & & 2 \\
\hline-0.15 to -0.01 & 14 & 8 & -0.15 to -0.01 & 36 & 16 & -0.33 to -0.15 & 20 & 26 \\
\hline-0.01 to 0.01 & 1 & 0 & -0.01 to 0.01 & 4 & 2 & -0.15 to -0.01 & 19 & 12 \\
\hline 0.01 to 0.15 & 4 & 3 & 0.01 to 0.15 & 6 & 19 & -0.01 to 0.01 & 1 & 1 \\
\hline 0.15 to 0.66 & 4 & 19 & 0.15 to 0.33 & & 2 & 0.01 to 0.15 & 6 & 5 \\
\hline
\end{tabular}


(a)

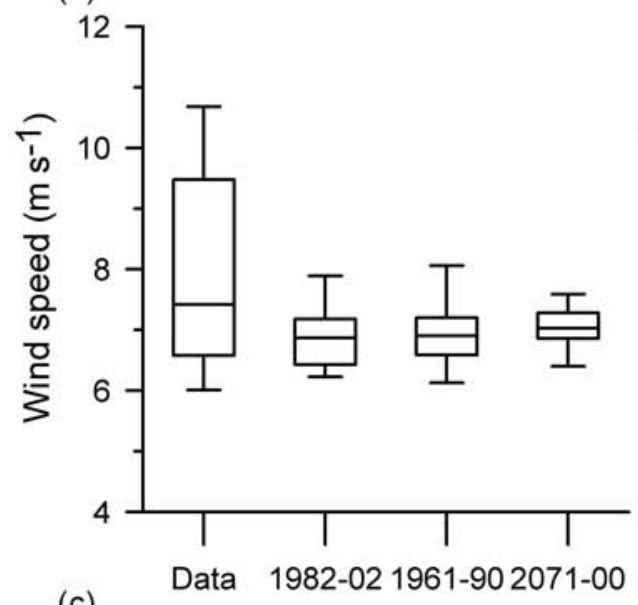

(b)
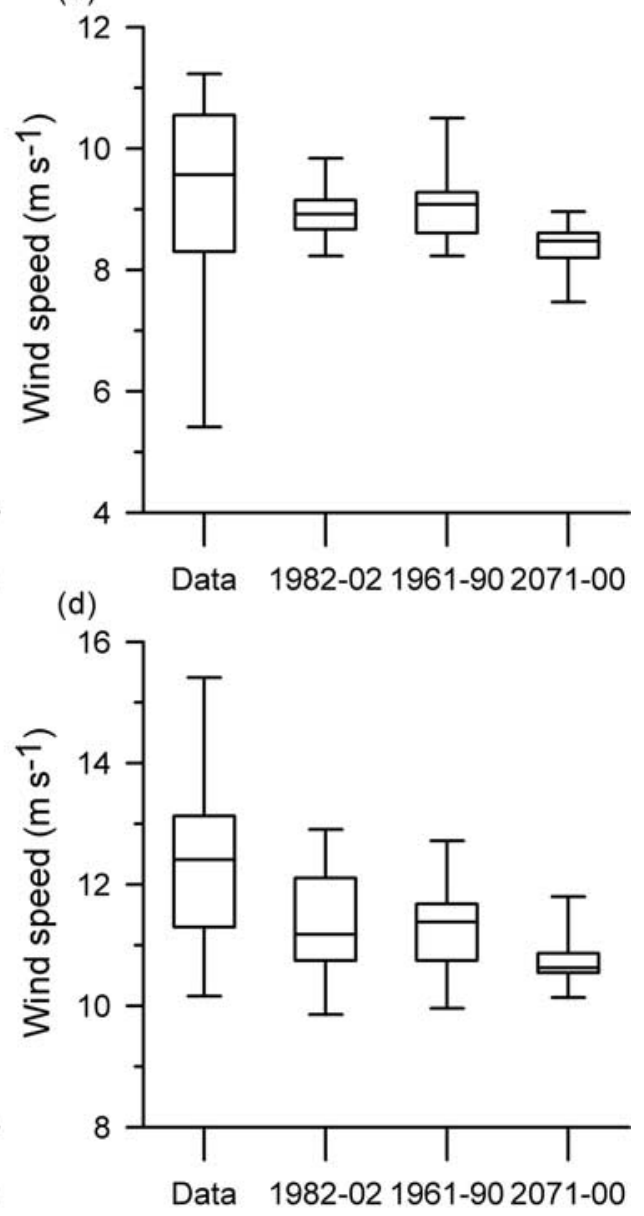

Figure 7. Box plots summarizing annual realizations of the 90th percentile wind speed at four Scandinavian capital cities, (a) Oslo, (b) Stockholm, (c) Helsinki, and (d) Copenhagen, derived from data collected during 1982-2002 (Data) and downscaling for three temporal windows, 1982-2002, 19611990, and 2071-2100.

increases in energy density and 90th percentile wind speed, particularly during winter, are located in the northwest of the domain and up the Scandic Peninsula (Figure 6). The sites that exhibit lower energy density, 90th percentile and mean wind speeds are predominantly located in the center of the domain.

[26] The empirical downscaling approach was also applied to examine interannual variability of the wind speed parameters. In this analysis the 360 realizations of pressure gradient and relative vorticity from each AOGCM year were used to derive downscaled Weibull A and k parameters at each station for each year in three time windows (19822002, 1961-1990, and 2071-2100). The downscaling approach tends to underestimate the interannual variability of the 90th percentile wind speed (and the other descriptors) relative to the observations in 1982-2002 (Figure 7), but the downscaled results for 1982-2002 at each of the Scandinavian capitals shown fall within the range of observations from 1982-2002. The downscaling "predictions" are better for the less topographically complex sites (e.g., Helsinki) where thermotopographic mesoscale flows are less likely to influence wind regimes. The downscaled results for 1961-1990 and 2071-2100 show some weak evidence of reduced interannual variability of the 90th percentile wind speed at the end of the C21st, although further work should be conducted to assess the robustness of this finding.

[27] As in the comparison with the NNR data (section 2), the RCAO derived wind speeds from grid cells containing each of the 46 stations underestimate the mean values derived from the empirical downscaling in 1961-1990 (and 2071-2100), particularly at sites characterized by high observed wind speeds (Figure 8a). Although the grid cell average mean wind speeds from the RCAO simulations for 1961-1990 and 2071-2100 show a high correlation with empirically downscaled station values (Figure 8a), the changes in wind speed parameters from the empirical downscaling (Figure 6) are in contrast to those derived from RCAO simulations using ECHAM4/OPYC3 derived boundary conditions for these time periods (Figure $8 \mathrm{~b}$ ). The RCAO simulations exhibit higher mean wind speeds during 2071-2100 for the A2 emission scenario than during 1961-1990 over the entire domain with the exception of the southwest corner [Pryor et al., 2005a]. The normalized change in mean wind speed between 1961-1990 and 20712100 (computed as [mean(2071:2100) - mean(1961:1990)]/ 

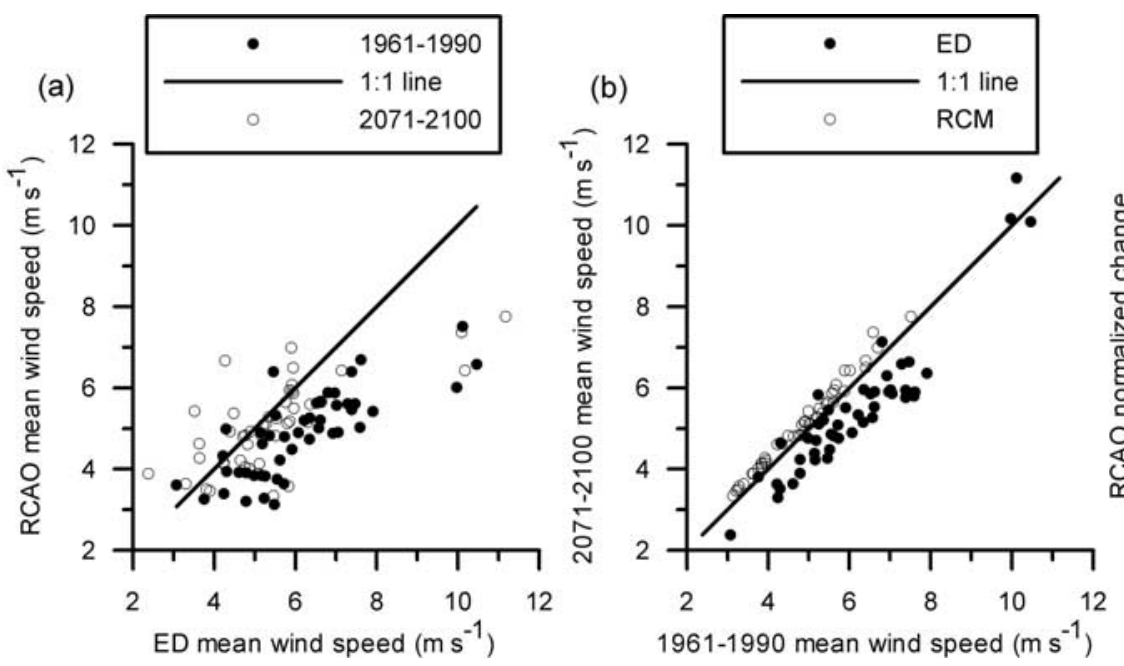

(c)

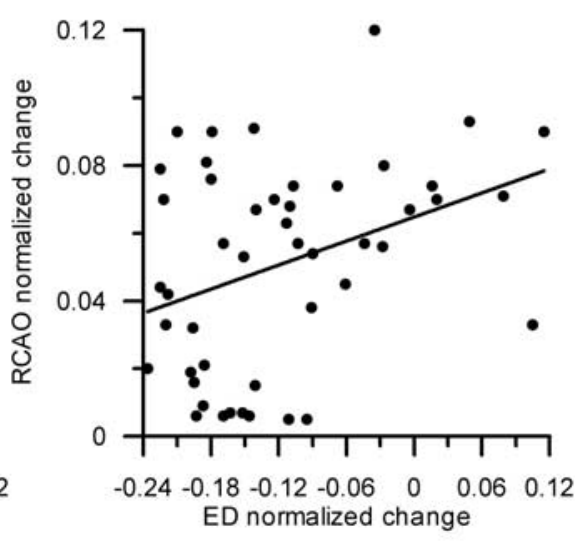

Figure 8. (a) Comparison of grid cell average mean wind speed from the RCAO for 1961-1990 and 2071-2100 versus station mean wind speed from the empirical downscaling for each of the 46 stations and the grid cells containing the station locations. Regression of the grid cell mean wind speed from the RCAO and the station mean wind speed from the empirical downscaling (ED) for 1961-1990 has a regression coefficient of 0.73 (i.e., RCAO mean wind speed $=0.78 \mathrm{ED}$ mean wind speed, $\mathrm{r}^{2}=0.98$ ), while that for 2071-2100 has a coefficient of $0.90\left(\mathrm{r}^{2}=0.96\right)$. (b) Scatterplots of the RCAO mean wind speed at grid cells containing the station for 1961-1990 and 2071-2100. Also shown are the empirically downscaled station mean wind speeds for these periods. (c) Comparison of grid cell average change in mean wind speed between 1961-1990 and 2071-2100 projected from the RCAO simulation and ED for each of the 46 stations. The line shows the regression fit to the data $(r=0.36)$. Note the axes in this frame have different scales.

mean(1961:1990)) from each station derived using empirical downscaling and those for the closest grid cell as simulated using the RCAO differ in magnitude and sign (Figure 8c). The cause for the discrepancy between the projected changes from the two downscaling methods has yet to be fully resolved, although there are some commonalities in that the sites that exhibit the largest decrease in 2071-2100 in the empirical downscaling are typically located in grid cells that exhibit the smallest increases in the dynamical downscaling. The few previous attempts to downscale winds have not focused on comparative analyses of dynamical versus empirical approaches, and evaluations of surface parameters as simulated using RCM have tended to focus on temperature and precipitation [Mearns et al., 1999]. The sites that exhibit the largest discrepancies are not characterized by lower-quality Weibull fits to the wind speed data, or lower explanatory power of the empirical downscaling equations. However, several of these sites are located in regions of relatively complex terrain or land cover heterogeneity and hence may exhibit localized effects not resolved by the RCAO modeling (scales of 10-40 km have been previously demonstrated to be unable to capture the full variability of $10 \mathrm{~m}$ wind speeds [Räisänen et al., 2004; de Rooy and Kok, 2004]).

\section{Summary}

[28] We present a probabilistic approach to empirical downscaling of near-surface wind speed and energy density. The technique uses the mean and standard deviation of relative vorticity at $500 \mathrm{hPa}$ and mean sea level pressure gradients computed using output from the ECHAM4/OPYC3
AOGCM as the predictors, while the predictands are descriptors of the probability distribution of near-surface wind speeds. We demonstrate that this approach generates accurate depictions of the wind climate during the transfer function conditioning period and then apply the downscaling to examine changes between 1961-1990 and 2071-2100 which are then compared to the results of dynamical downscaling using a RCM with boundary conditions supplied by the ECHAM4/OPYC3 AOGCM. The empirical downscaling projects small decreases in mean wind speed, 90th percentile wind speed and energy density in 2071-2100 relative to 1961-1990 (Figure 6). These changes are larger than the discrepancy between observed and downscaled values in the conditioning period (1982-2002) (Table 2) but are smaller magnitude than current interannual variability (e.g., Figure 7). Conversely, simulations conducted using the Rossby Centre RCM indicate evidence for a small increase in the annual wind energy resource over northern Europe between the end of the 20th century and the end of the 21 st century. Further work is required to resolve the differences in results from the two downscaling approaches.

[29] The empirical downscaling approach we propose appears to have great potential for wind speed and energy applications and may also be applicable to other geophysical variables. Additionally, although applied here to long time windows, it is applicable to any temporal window for which stable probability distributions can be derived (e.g., annual as demonstrated herein). However, there are a number of caveats that should be applied to the research presented herein; the most important are as follows.

[30] 1. It is assumed that the wind speed distribution is well described using the two-parameter Weibull distribu- 
tion. While this is generally true, it is not uniformly the case especially in locations that are characterized by mixed forcing of the flow (e.g., a wind climate with distinct components from the synoptic scale and local thermotopographic circulations may exhibit a probability distribution that is not well-described by the two-parameter Weibull distribution).

[31] 2. The selection of our downscaling predictors was based on a priori knowledge, and evaluation of alternative predictors for northern Europe. It is possible that other large-scale descriptors may be more appropriate in other domains.

[32] 3. Projected changes in the wind speed probability distribution documented herein are sensitive to the selection of the AOGCM from which the predictors are derived, hence future work will incorporate analyses of multiple AOGCM simulations.

[33] 4. As shown, individual locations differ in terms of the degree of coupling to the regional scale flow, hence comparison of empirically downscaled data with grid cell averaged data derived using a RCM should be undertaken with care and may explain some of the discrepancy between the RCMderived and empirically downscaled wind projections.

[34] Acknowledgments. This research greatly benefited from discussions with G. Takle of Iowa State University. We also acknowledge E. Roeckner of MPI for making the ECHAM model results accessible to us and E. Kjellström of the Rossby Center at SMHI for the RCAO simulations. The NNR products are available from http://www.cdc.noaa.gov/cdc/ reanalysis. Limited financial support for this research was provided by "Impacts of Climate Change on Renewable Energy Sources and their Role in the Energy System: 2003-2006" project funded by the Nordic Energy Research. The computational component of the research was made possible by the following grants to Indiana University from IBM, inc. (Shared University Research) and the National Science Foundation (grant 0116050).

\section{References}

Allen, M., and W. Ingram (2002), Constraints on future changes in climate and the hydrologic cycle, Nature, 419, 224-232.

Ambrose, J., and D. Vergun (1997), Simplified Building Design for Wind and Earthquake Forces, 3rd ed., 368 pp., John Wiley, Hoboken, N. J.

Bijl, W. (1997), Impact of a wind climate change on the surge in the southern North Sea, Clim. Res., 8, 45-59.

Buishand, T. A., and T. Brandsma (2001), Multisite simulation of daily precipitation and temperature in the Rhine basin by nearest-neighbor resampling, Water Resour. Res., 37, 2761-2776.

Cavazos, T., and D. Rivas (2004), Variability of extreme precipitation events in Tijuana, Mexico, Clim. Res., 25, 229-243.

Changnon, S. A., E. R. Fosse, and E. L. Lecomte (1999), Interactions between the atmospheric sciences and insurers in the United States, Clim. Change, 42, 51-67.

Christensen, J., and O. B. Christensen (2003), Severe summertime flooding in Europe, Nature, 421, 805-806.

Conradsen, K., L. B. Nielsen, and L. P. Prahm (1984), Review of Weibull statistics for estimation of wind speed distributions, J. Clim. Appl. Meteorol., 23, 1173-1183.

Covey, C., K. AchutaRao, U. Cubasch, P. D. Jones, S. Lambert, M. Mann, T. Phillips, and K. Taylor (2003), An overview of results from the Coupled Model Intercomparison Project, Global Planet. Change, 37, $103-133$.

de Rooy, W. C., and K. Kok (2004), A combined physical-statistical approach for the downscaling of model wind speeds, Weather Forecast., 19, $485-495$.

Dickinson, R. E., R. Errico, F. Giorgi, and G. T. Bates (1989), A regional climate model for the western United States, Clim. Change, 12, 383422.

Evans, J. P., R. B. Smith, and R. Oglsby (2004), Middle East climate simulation and dominant precipitation processes, Int. J. Climatol., 24, $1671-1694$.

Giorgi, F., and L. O. Mearns (1999), Introduction to special section: Regional climate modeling revisited, J. Geophys. Res., 104, 63356352.
Giorgi, F., and L. Mearns (2002), Calculation of average, uncertainty range and reliability of regional climate changes from AOGCM simulations via the "reliability ensemble averaging" (REA) method, J. Clim., 15, $1141-1158$.

Giorgi, F., M. Marinucci, and G. Visconti (1992), A 2XCO2 climate change scenario over Europe generated using a limited area model nested in a general circulation model: 2. Climate change scenario, J. Geophys. Res., 97, 10,011-10,028.

Hsu, S. A. (1988), Coastal Meteorology, 260 pp., Elsevier, New York.

Huth, R. (2004), Sensitivity of local daily temperature change estimates to the selection of downscaling models and predictors, J. Clim., 17, 640652 .

Huth, R., J. Kysely, and M. Dubrovsky (2001), Time structure of observed, GCM-simulated, downscaled and stochastically generated daily temperature series, J. Clim., 14, 4047-4061.

Intergovernmental Panel on Climate Change (IPCC) (2000), Emissions Scenarios 2000, 570 pp., Cambridge Univ. Press, New York.

Jungo, P., S. Goytette, and M. Beniston (2002), Daily wind gust speed probabilities over Switzerland according to three types of synoptic circulation, Int. J. Climatol., 22, 485-499.

Kalnay, E., et al. (1996), The NCEP/NCAR 40 reanalysis project, Bull. Am. Meteorol. Soc., 77, 437-471.

Karl, T., W. Wang, M. Schlesinger, R. Knight, and D. Portman (1990), A method of relating general circulation model simulated climate to the observed local climate. part I: Seasonal statistics, J. Clim., 3, 1053-1079.

Kistler, R., et al. (2001), The NCEP-NCAR 50 year reanalysis: Monthly mean CD-ROM and documentation, Bull. Am. Meteorol. Soc., 82, 247267.

Klein Tank, A. M. G., G. P. Konnen, and F. Selten (2005), Signals of anthropogenic influence on European warming as seen in the trend patterns of daily temperature variance, Int. J. Climatol., 25, 1-16.

Latham, J., and M. H. Smith (1990), Effect on global warming of winddependent aerosol generation at the ocean surface, Nature, 347, 372373

Lynn, B. H., L. Druyan, C. Hogrefe, J. Dudhia, C. Rosenzweig, R. Goldberg, D. Rind, R. Healy, J. Rosenthal, and P. Kinney (2004), Sensitivity of present and future surface temperatures to precipitation characteristics, Clim. Res., 28, 53-65.

McAvaney, B., C. Covey, S. Joussaume, V. Kattsov, A. Kitoh, W. Ogana, A. J. Pitman, A. Weaver, R. A. Wood, and Z.-C. Zhao (2001), Model evaluation, in Climate Change 2001: The Scientific Basis, edited by J. T. Houghton et al., pp. 471-524, Cambridge Univ. Press, New York.

Mearns, L. O., I. Bogardi, F. Giorgi, I. Matyasovszky, and M. Palecki (1999), Comparison of climate change scenarios generated from regional climate model experiments and statistical downscaling, J. Geophys. Res., 104(D6), 6603-6621.

Palmer, T. N., and J. Räisänen (2002), Quantifying the risk of extreme seasonal precipitation events in a changing climate, Nature, 415, 512514.

Pavia, E. G., and J. J. O’Brien (1986), Weibull statistics of wind speed over the ocean, J. Clim. Appl. Meteorol., 25, 1324-1332.

Pryor, S. C., M. Nielsen, R. J. Barthelmie, and J. Mann (2004), Can satellite sampling of offshore wind speeds realistically represent wind speed distributions? part II: Quantifying uncertainties associated with sampling strategy and distribution fitting methods, J. Appl. Meteorol., 43, 739750.

Pryor, S. C., R. J. Barthelmie, and E. Kjellström (2005a), Analyses of the potential climate change impact on wind energy resources in northern Europe using output from a regional climate model, Clim. Dyn., in press.

Pryor, S. C., R. J. Barthelmie, and J. T. Schoof (2005b), The impact of nonstationarities in the climate system on the definition of "a normal wind year": A case study from the Baltic, Int. J. Climatol., 25, 735-752.

Räisänen, J., U. Hansson, A. Ullerstig, R. Döscher, L. P. Graham, C. Jones, M. Meier, P. Samuelsson, and U. Willén (2003), GCM driven simulations of recent and future climate with the Rossby Centre coupled atmosphere-Baltic Sea regional climate model RCAO, Rep. Meteorol. Climatol. 101, 61 pp., Swed. Meteorol. and Hydrol. Inst., Norrköping.

Räisänen, J., U. Hansson, A. Ullerstig, R. Doscher, L. Graham, C. Jones, H. Meier, P. Samuelsson, and U. Willen (2004), European climate in the late twenty-first century: Regional simulations with two driving global models and two forcing scenarios, Clim. Dyn., 22, 13-31.

Roeckner, E., L. Bengtsson, J. Feichter, J. Lelieveld, and H. Rodhe (1999), Transient climate change simulations with a coupled atmosphere-ocean GCM including the tropospheric sulfur cycle, J. Clim., 12, 3004-3032.

Roulston, M. S., and L. A. Smith (2003), Combining dynamical and statistical ensembles, Tellus, Ser. A, 55, 16-30.

Sailor, D. J., and X. Li (1999), A semiempirical downscaling approach for predicting regional temperature impacts associated with climate change, J. Clim., 12, 103-114.

Schnur, R. (2002), The investment forecast, Nature, 415, 483-484. 
Seguro, J. V., and T. W. Lambert (2000), Modern estimation of the parameters of the Weibull wind speed distribution for wind energy analysis, J. Wind Eng. Ind. Aerodyn., 85, 75-84.

Stainforth, D., et al. (2005), Uncertainty in predictions of the climate response to rising levels of greenhouse gases, Nature, 433, 403-406.

Taylor, K. E. (2001), Summarizing multiple aspects of model performance in a single diagram, J. Geophys. Res., 106, 7183-7192.

Troen, I., and E. L. Petersen (1989), European Wind Atlas, 656 pp., Risø Natl. Lab., Roskilde, Denmark.

Viles, H. A., and A. S. Goudie (2003), Interannual, decadal and multidecadal scale climatic variability and geomorphology, Earth Sci. Rev., $61,105-131$

von Storch, H., B. Hewitson, and L. Mearns (2000), Review of empirical downscaling techniques, in Regional Climate Development Under Global Warming: Conference Proceedings RegClim Spring Meeting, edited by T. Iversen and B. A. K. Høiskar, Gen. Tech. Rep. 4, pp. 29-46, Jevnaker, Torbjornrud, Norway.
Wilby, R., L. Hay, W. Gutowski Jr., R. W. Arritt, E. S. Takle, Z. Pan, G. Leavesley, and M. Clark (2000), Hydrological responses to dynamically and statistically downscaled climate model output, Geophys. Res. Lett., 27 , 1199-1202.

Zhang, X. C., M. A. Nearing, J. D. Garbrecht, and J. L. Steiner (2004), Downscaling monthly forecasts to simulate impacts of climate change on soil erosion and wheat production, J. Soil Sci. Soc. Am., 68, 13761385 .

R. J. Barthelmie, Department of Wind Energy and Atmospheric Physics, Risø National Laboratory, DK 4000 Roskilde, Denmark.

S. C. Pryor, Atmospheric Science Program, Department of Geography, Indiana University, Bloomington, IN 47405, USA. (spryor@indiana.edu)

J. T. Schoof, Center for Ocean-Atmospheric Prediction Studies, Florida State University, Tallahassee, FL 32306, USA. 